\title{
LA MISERICORDIA, CARISMA DEL PASTOREO SACERDOTAL Una óptica bíblica
}

DOI: https://doi.org/10.52039/seminarios.v62i216.141

KONRAD SCHAEFER*

Después de esbozar la parábola sobre el extremo de hasta dónde llega el amor Dios hacia su pueblo, reflexionaré sobre la figura del pastor de Israel, como se presenta en tres paradigmas del Antiguo Testamento y concluiré con un aspecto del perfil del «Amable Pastor»" ${ }^{\text {. }}$

Un esquema se repite a lo largo de la Biblia: la gracia creativa de Dios en el mundo (Alianza), la caída (pecado) del ser humano, seguido por la corrección (castigo) de Dios; el correctivo de Dios va mitigado por su gracia (= misericordia), y la consiguiente nueva creación. Los textos referidos son la parábola de la vida matrimonial de Oseas (Oseas 1-3), la apostasía de Israel y la mediación de Moisés (Éxodo 32-34), la toma de conciencia de David después de su pecado (Salmo 51) y, en el Nuevo Testamento, la parábola del Pastor Amable (Juan 10, 11-18).

\section{LAS NUPCIAS ENTRE DIOS Y SU PUEBLO (Oseas 1-3)}

Para empezar, te pregunto: ¿Alguna vez en la vida te enamoraste? Y ¿cómo recorriste la experiencia del enamoramiento? ¿Hasta dónde tenías que sufrir tu propio apego y el dolor de un amor no correspondido?

Les cuento una parábola. Un joven se enamoró de una joven. Por un tiempo la miraba y admiraba, mientras la atracción iba creciendo, el joven sabía que la cortejada tenía varios pretendientes, rivales que le ofrecían más de lo que él mismo podía dar, pero él no se dio por vencido. Un buen día, declaró su amor y se inició el noviazgo. Se daba cuenta de que su novia seguía saliendo con otros amigos; también sabía que ella le iba a fallar. Sin embargo, se casaron y tuvieron un hijo, luego una hija y otro hijo, pero pronto la esposa se fastidiaba

* Monje benedictino del monasterio Nuestra Señora de los Ángeles en Cuernavaca, México. Es profesor de Sagrada Escritura en la Universidad Pontificia de México.

1. La frase ho poimen ho kalós, «el bueno» o «excelente pastor», de Juan 10, 11.14, que se refiere a su calidad moral, la interpreto libremente como «Amable Pastor». 
de la vida familiar. Le dijo a su desconcertado esposo: te amo..., me amas, pero tu amor no me llena. Ella empezó a salir con sus antiguos amigos a las salas de fiestas, a bailes y celebraciones; buscaba aventuras ardientes; se divertía con los bailes; disfrutaba los perfumes, las alhajas, los vinos y la ropa fina que le venían como regalos. Recibía la pasión de todo el mundo, pero cada regalo de sus parejas pasajeras era una atadura más a su libertad, hasta que, desde su nueva esclavitud en la vida afectiva, se acordó de su esposo, el único que la amaba sin condiciones y que siempre aguardaba el día que su esposa se hartara del amor de la piel y volviera a su amor fiel. Después de sumirse en este amor ilusorio que acabó en la miseria, ella volvió a su esposo, quien le abrió la puerta. Cuando la extraviada esposa vuelve, el «Amable Esposo» no la recrimina, sino la recibe con todo su amor de siempre.

La parábola de la familia del profeta Oseas se empalma con la historia de Dios con su pueblo. Oseas se casó con Gómer, para quien la fidelidad era imposible, y en su matrimonio revivieron los esponsales entre Dios y su pueblo: la paciencia sin fin del esposo, el amor constante y la misericordia. A través de su propia historia afectiva, el profeta reflexiona la eficacia del amor de Dios con su pueblo Israel (Os 1-3). Su fidelidad se conoce en hebreo como jésed ${ }^{2}$, que se refiere a la alianza, la fidelidad incansable que no se traiciona a sí misma; en el lenguaje del compromiso se conoce como lealtad, favor, gracia, misericordia y compasión. Jésed, como amor fiel que no se remata, tiene dos rostros. Uno es el que se mantiene vigente la alianza, no importa la respuesta de la otra parte. Es amor firme que no depende de la respuesta correspondiente. Por esta fidelidad férrea que no se niega a sí misma, nace el otro rostro, que es la misericordia, que retrata el profeta Oseas, siempre a la espera de la vuelta de su esposa adúltera. Cuando ella vuelve al hogar, Oseas no mira a una extraviada, sino a la esposa de siempre, a la única.

El jésed abarca la lealtad o la fidelidad infalible ligada a la alianza; en primer lugar, es la virtud de la fidelidad a la cual las dos partes están comprometidos. Cuando una parte falla a la otra, ¿se cancela la alianza? Pero Dios es coherente, y no se niega a ser fiel a sí mismo, por lo cual la infidelidad de su pareja le mueve a una nueva expresión de su jésed, que alcanza la misericordia y revela el amor constante y benévolo sin condiciones, amor que acoge a la esposa en casa y la perdona. Su inquebrantable compromiso a la Alianza salva a su pueblo.

El salmista, confiado de la gracia y la salvación (13, 6; cf. 21, 8), se verá siempre acompañado de este amor complaciente $(23,6)$ : «Bondad y jésed me acompañarán todos los días de mi vida» ${ }^{3}$. Según el salmo 103, una especie de «himno nacional» en honor al jésed, Dios corona al pecador con su jésed, re-

2. El vocablo jésed, Os 2, 21; 4, 1; 6, 4; 10, 12; $12,7$.

3. El salmo 89 recuerda este jésed y lealtad a David y su descendencia (v. 2-3) que jamás fallará, a pesar de la infidelidad humana (v. 29-38). 
novándolo con su perdón (103, 3-5.8-12.17-18). Su jésed es eterno, por lo cual el poeta invita a la asamblea litúrgica a alabarlo $(106,1$; 107, 1.8.15.21; 118, 1 ; 136, 1): «Den gracias al Señor porque es bueno, porque es eterno su jésed» ${ }^{4}$. Las intervenciones de «Amable Dios» a favor de su pueblo encuentran su fuente en el jésed; más aún, la misma creación es fruto del jésed divino, que es amor que no se encierra en sí mismo sino, por su energía interna, promueve la vida.

El jésed de Dios pide al ser humano corresponder como jasîd, «amigo de Dios», ser íntegro y sincero $(12,2 ; 43,1)$, leal y fiel $(149,1.5 .9$; cf. 109, 16). En un momento, Dios se queja del ser humano: «No hay fidelidad ni jésed, ni conocimiento de Dios en esta tierra» (Os 4, 1), y recalca: «Yo quiero jésed, no sacrificio, conocimiento de Dios, más que holocaustos» (Os 6, 6). Se entiende que, al jésed recibido de Dios se responde con la alegre sumisión a su voluntad y la misericordia con el prójimo.

La corrupción religiosa de Israel, en la época del profeta Oseas, repercutía en desigualdad social. Gran parte del pueblo había dejado de creer en el Dios liberador; adoraba ídolos, exaltando el materialismo, el poder político y fomentando una religiosidad funcional. La parábola del matrimonio muestra que Dios no es ajeno al dolor ni indiferente ante la injusticia; tiene entrañas de misericordia y una inagotable capacidad de perdonar, pero su misericordia es en función de que su amado pueblo le responda con jésed, que se describe en términos de fidelidad y misericordia.

Gómer se separó de su esposo Oseas y malbarató su existencia con otros amantes; de un modo análogo, respecto a los esponsales de Dios con Israel, el pueblo elegido se sumió en la idolatría -que se escribe adulterio- y la injusticia, y su infidelidad determinó la destrucción de Israel y envenenó a Judá con la pócima amarga del exilio. La esposa Gómer, metáfora de la desventura de Israel y Judá, sorbió el desconsuelo del hambre y el desamparo. Sin embargo, a razón del jésed de Dios, siempre fiel a la Alianza, se realiza la reconciliación.

Así que la capacidad del jésed que anida en las entrañas del «Amable Dios» es más fuerte que la traición. Cuando Gómer regresa al hogar, Oseas no le recrimina; la acoge con misericordia, que reconstruye la vida matrimonial. La lógica de la misericordia discurre de una manera distinta de la razón y de los instintos humanos. El profeta enseña que se puede contar con el jésed, sin importar cuánto la otra parte falte a su compromiso.

Oseas, teólogo sensible y creativo, narra una parábola del amor no correspondido en la que, a pesar de la infidelidad de la mujer, el esposo no deja de amarla. El matrimonio tempestuoso es la Alianza entre "Amable Dios» y su pueblo. Que Dios le pida al profeta conquistar de nuevo el amor de la mujer

4. El poeta presenta a Dios como creador y salvador caracterizado por el jésed; la frase «porque es eterno su jésed» (Salmo 136), forma la aclamación de cada versículo y traza la historia, desde su creación hasta el alimento de cada día, como expresión del jésed divino. 
(Os 3, 1-5) muestra que Dios no se cansa de perdonar y que se compromete a restaurar la Alianza con el pueblo. La propia vida afectiva del profeta se convierte en símbolo: igual que Oseas ama a la mujer infiel, Dios ama a su pueblo; lo mismo que el insistente jésed del profeta alcanzará el retorno de la esposa, el jésed infalible de Dios logrará la vuelta de su pueblo, y la creación del mundo nuevo según la virtud de Dios, ahora correspondido en la vida del pueblo.

\section{LA APOSTASÍA Y LA MISERICORDIA DE DIOS (Ex 32-34)}

Después de la liberación de la esclavitud de Egipto, llegamos al desierto del Sinaí, poco después de concertar la Alianza entre Dios y el pueblo. El pecado original del nuevo pueblo de Dios es la idolatría (Ex 32-34) $)^{5}$. La historia sigue esta línea. Mientras Moisés permanecía en el monte cuarenta días con sus noches (cf. 24, 18), Aarón se encargaba del rebaño y no fue capaz de negarse a las exigencias del pueblo, que le pidió un dios palpable (32, 1-6). El contraste entre Moisés y Aarón es marcado: El primero, en el monte en diálogo con Dios; Aarón, en la llanura, toma decisiones extemporáneas, sin considerar a Dios. Ya desde su niñez, el pueblo rechazó al «Amable Dios» que le había dado la vida. El relato hace hincapié en que el becerro de plata y oro era hechura de manos humanas, y así llegó a ser como cualquiera de los ídolos que tienen boca y no hablan, ojos y no ven ${ }^{6}$. La idolatría acaba en una juerga, que replica el rito que selló la Alianza: «Al día siguiente se levantaron de madrugada y ofrecieron holocaustos y presentaron sacrificios de comunión. El pueblo se sentó a comer y beber, y después se levantó para divertirse» (32, 6; cf. Ex 24, 5-11). Entre Dios y su pueblo, siempre hubo un puente, Moisés, el mediador, que aboga a favor de la vida del pueblo, a favor del perdón y la misericordia hacia los infractores.

El diálogo entre Dios y Moisés (32, 7-14) esboza el patrón que se repite en la narración de la salvación: Alianza (= creación), caída, castigo o corrección de parte de Dios, mitigación (que se escribe misericordia) y nueva creación. Con la fabricación del becerro de oro, el pueblo se aparta del camino y quebranta la Alianza ${ }^{7}$. Dios ya no le llama «mi pueblo» (Os 2, 8), sino «tu pueblo» (de Moisés) (v. 7): «Se ha pervertido tu pueblo, el que sacaste del país de Egipto».

5. Moisés intercede y Dios se muestra fiel a su Alianza $(32,1-14)$. Según el relato, el pueblo toma conciencia de su pecado, del alcance y las implicaciones del castigo y, sobre todo, de la revelación de Dios «misericordioso y clemente, tardo a la cólera y rico en amor y fidelidad» (Ex 34, 6). Con este relato, el teólogo enseña: Dios es uno y exige una amistad exclusiva; elige al pueblo, lo libera de las amenazas, pero sobre todo de su propia inconstancia; reafirma la Alianza y se manifiesta como justo, pero cuyo carácter de justicia se define en términos de la misericordia, como quien considera la necesidad y la habilidad de cada persona (Ex 16, 8: "Que cada uno recoja cuanto necesita para comer»).

6. Cf. Sal 106, 19-20; 115, 5-6.

7. Cf. Dt 9, 7-14, texto sinóptico que narra el episodio. 
Es un pueblo obstinado -«de dura cerviz»-, descripción que se oye repetidas veces ${ }^{8}$. Su desviación en el Sinaí recuerda el pecado en el paraíso (Gn $3,19)^{9}$. Dios responde al pecado con el castigo, que viene teñido por la misericordia, que tiene como consecuencia una nueva creación.

Como en otro tiempo Abrahán a favor de la ciudad de Sodoma (Gn 18, $22-$ 23), Moisés intercede ante Dios. Él argumenta que Dios sacó al pueblo de una esclavitud en Egipto, y no le conviene echarse para atrás: «¿Por qué, oh Yahvé, ha de encenderse tu ira contra tu pueblo, el que tú sacaste del país de Egipto?» (v. 11)? La iniciativa de Dios en la promesa a Abram, la elección del pueblo y la Alianza forman la base para la misericordia, frente a cualquier defecto $o$ desviación. Se entiende en esta iniciativa, que Dios es fiel a sí mismo, que él mismo interviene y corrige la falla de su pueblo, pero su castigo es con el afán de encausar al pueblo hacia una nueva creación, por lo cual, dentro del mismo castigo está programada la misericordia, que templa el castigo.

El castigo (32, 15-24) está cargado de significado. En primer lugar, Moisés, defensor de la causa de Dios, hizo añicos las tablas de piedra de las diez Palabras grabadas por Dios (vv. 16.19), un gesto que dramatiza la fractura de la Alianza: en el pecado, se pierde consciencia de la ley y la sensibilidad a la maldad (cf. Am 8, 11-12). Moisés tomó la estatua del becerro, la quemó y la molió en polvo, algo que no tiene consistencia. Las tablas eran «obra de Dios y la escritura era escritura de Dios» (v. 16); el becerro era hecho por mano humano. Moisés esparció el polvo del becerro en el agua y dio a beber los residuos al pueblo (v. 20), gesto que enseña que el pecado es personal: quienes pecaron estaban obligados a tragar el producto de su pecado. Recuerda el pecado de la primera mujer y del primer hombre, cuyo acto de morder del fruto prohibido mereció el castigo de perder el paraíso ${ }^{10}$.

EI Señor echa la culpa al pueblo y la responsabilidad a Moisés (33, 1-6), quien se recluye en la tienda del encuentro para hablar con Dios «cara a cara, como habla un hombre con su amigo» $(33,11)$. Moisés pide $(33,12-17)$ a Dios que le enseñe el camino y que acompañe a su pueblo. El «camino» no es sólo la travesía del desierto; es su modo de conducirse. En una descripción antropomórfica, Dios había determinado no caminar con su pueblo (33, 3: «Yo no subiré contigo, pues eres un pueblo obstinado y te destruiría en el camino»). Moisés intercede para

8. La expresión «dura cerviz», v. 9; cf. 33, 3.5; 34, 9; Dt 9, 6.13.

9. También, si se considera la presentación de Génesis 3-11, hace pensar en el pecado que dio origen al diluvio (cf. 6, 6-7); el del descubrimiento de la desnudez de Noé (9, 21-27), y el de Babel (11, 1-9).

10. El castigo en Ex 32 niega al pueblo la presencia sensible de Dios y recuerda el castigo de Adán (33, 1-6; cf. Gn 3, 24). Aquél era el pecado del individuo, después de su creación; éste es el del pueblo después de su constitución por la Alianza. Allí los expulsó de su presencia; ahora se niega a acompañarlos en su recorrido hacia la Tierra prometida. Allí ordena al ángel que bloquee el acceso a los bienes del paraíso; ahora nombra a Moisés intermediario y exige a los israelitas despojarse de las joyas que habían usado para fabricar el becerro de oro (vv. 5-6). 
que Dios revoque su decisión. Su argumento es que, si goza del favor divino, si existe un trato tan íntimo, el «Amable Dios» no puede abandonarlos (vv. 15-16). Dios accede a la petición (v. 17): «Yahvé respondió a Moisés: haré también esto que me pides, pues has obtenido mi favor (jnn)». De esta forma la misericordia de Dios seguirá siendo su marca distintiva hacia Israel.

Encontramos dos ideas fundamentales para la fe israelita: primera, sin la presencia de Dios en medio de ellos, este pueblo no habría subsistido; y segunda, el papel principal del mediador Moisés es un papel que desempeñaban los profetas. Ambas realidades, presencia divina y mediación humana, se basan en el jésed (= misericordia, o fidelidad que se expresa como misericordia).

Ahora Moisés pide un conocimiento íntimo de Dios: Ver su gloria, su naturaleza divina. Pero, siendo Dios trascendente, es imposible que el ser humano, criatura limitada, lo comprenda o lo vea de frente ${ }^{11}$. El teólogo expresa el encuentro en estos términos: «Moisés dijo a Yahvé: 'Déjame ver tu gloria'. Él le contestó: 'Yo haré pasar ante tu vista toda mi bondad (tôb) y pronunciaré delante de ti el nombre de Yahvé; pues concedo mi favor (jnn) a quien quiero (jnn) y tengo misericordia (rejem) con quien quiero (rajam)... Pero mi rostro no podrás verlo, porque nadie puede verme y seguir con vida'. Yahvé añadió: 'Aquí hay un sitio junto a mí; ponte sobre la roca. Al pasar mi gloria, te meteré en la hendidura de la roca y te cubriré con mi mano hasta que yo haya pasado. Luego apartaré mi mano para que veas mis espaldas; pero mi rostro no lo verás'» (Ex 33, 18-23).

La visión de Dios es la prueba de un favor singular a Moisés, «amigo de Dios» (Nm 12, 7-8; Dt 34, 10). Pero no es una visión clara, sino de espaldas, como para indicar que el hombre sólo descubre a Dios después de que haya pasado, en las huellas que deja. Aquí, Dios no concede una foto de alta definición de su ser misterioso, sino que permite que Moisés y el pueblo lo contemple al pasar, en sus huellas de misericordia. Este encuentro sensible fue un privilegio que volverá a repetirse cuando el profeta Elías encuentra a Dios no en el terremoto ni en la tormenta ni en el espectáculo, sino en la «suave brisa» (1 Re 19, 9-13)12: «Le dijo: 'Sal y permanece de pie en el monte ante Yahvé'. Entonces Yahvé pasó y hubo un huracán tan violento que hendía las montañas y quebraba las rocas ante Yahvé; pero en el huracán no estaba Yahvé. Después del huracán, un terremoto; pero en el terremoto no estaba Yahvé. Después del terremoto, fuego, pero en el fuego no estaba Yahvé. Después del fuego, el susurro de una brisa suave».

11. Una rúbrica repetida es «nadie puede ver el rostro de Dios y permanecer con vida» (cf. v. 20; Ex 3, 6; 19, 21; Lv 16, 2; Jue 6, 22-23; cf. Gn 32, 31). Una infranqueable distancia separa la santidad de Dios y la indignidad del ser humano; con solo ver a Dios el hombre muere. Sin embargo, se comprende que Dios conceda a Moisés un favor excepcional (cf. Dt 34, 10, y además 1 Re 19, 13; Is 6, 2; cf. Jn 1, 14.18; 1 Cor 13, 12; 2 Cor 3, 18; Hb 11, 1).

12. Traduzco la expresión que las versiones tienen como «suave brisa» como «un silencio elocuente». Estos dos personajes aparecerán en la transfiguración (Mt 17, 1-7), donde se hizo patente la divinidad de Jesús. Sólo él ha visto a Dios y lo ha dado a conocer (cf. Jn 1, 18). 
La teofanía esta descrita con sobriedad $(34,1-5)$ con los mismos elementos señalados en el capítulo 19: Preparación esmerada de Moisés (vv. 4-5; cf. 19, 10-11); aparición de Dios dentro de la nube (v. 5; cf. 19, 16-20) ${ }^{13}$.

A la invocación de Moisés, Dios se manifiesta ${ }^{14}$ : "Yahvé pasó por delante de él y Moisés exclamó: 'Yahvé, Yahvé, Dios misericordioso y clemente, tardo a la cólera y rico en amor y fidelidad, que mantiene su amor por mil generaciones y perdona la iniquidad, la rebeldía y el pecado'» (34, 6-7). En esta formulación se recalcan los atributos de Dios, la fidelidad y, sobre todo, la misericordia, que comprueba su fidelidad. La persona, consciente de su pecado, tiene acceso a Dios desde la certeza de que Dios fiel es misericordioso. «Es en esta revelación central donde el pueblo elegido y cada uno de sus miembros encontrarán, después de toda culpa, la fuerza y la razón para dirigirse al Señor con el fin de recordarle lo que él había revelado de sí mismo y para implorar su perdón» ${ }^{15}$.

La misma dinámica atraviesa la historia de Israel, y a la luz de ella entendemos el mensaje de los profetas. Es la instrucción del episodio del becerro de oro, actualizado en otros momentos difíciles del pueblo. Pensemos en la época del destierro (587-534 a.C.) cuando todo se había perdido: su templo, su rey, su patrimonio y su identidad como pueblo de Dios. La relectura de este pasaje llevó a un renacimiento de la fe y de la esperanza. Fe en que Dios, comprometido con el pueblo desde tiempos de la esclavitud, que no los borró de la tierra en otras circunstancias difíciles, ahora tampoco los abandonará, siempre y cuando el pueblo reconozca sus culpas. «Amable Dios» asume un compromiso con Israel, no porque sea el pueblo mejor de todos, sino porque es pecador y es el lugar teológico de la misma «esperanza divina»-Dios también espera- en la conversión del pueblo, como respuesta a su trato misericordioso. Estos textos iluminan épocas de crisis y, al mismo tiempo, llenan de esperanza un futuro que, poco a poco, se presenta como posibilidad de reconstrucción después del exilio.

\section{LA TOMA DE CONCIENCIA DE DAVID (Sal $\left.51^{16}\right)$}

El retrato del pastor surge en parte de la persona de David, quien en su juventud apacentaba el rebaño de su familia (1 Sm 16, 11; 17, 34); de ahí los términos de su nombramiento como rey: «Tú apacentarás a mi pueblo Israel, tú serás el caudillo de Israel» (2 Sm 5, 2; cf. Sal 78, 70-71).

13. En comparación, el relato en Éxodo 19 destaca no la trascendencia divina, sino la familiaridad de Dios: «se detuvo allí junto a él» (v. 5), lo cual recalca la postura de la Alianza.

14. La repetición solemne de su nombre recalca, ante la asamblea israelita, la presentación litúrgica de sí mismo.

15. Juan Pablo II, encíclica Dives in misericordia (30 de noviembre de 1980), 4.

16. Según la enumeración de los salmos en la Liturgia de las horas, este salmo es más conocido como el Salmo 50, el «Miserere» En la mayoría de las versiones modernas de la Biblia, es el salmo 51. Aquí conservo la numeración bíblica. 
Un escriba situó el Salmo 51 en un momento crítico en la vida de David, adúltero y asesino ${ }^{17}$. Su encabezado - «Del maestro de coro. Salmo. De David. Cuando el profeta Natán lo visitó, después de haberse unido aquél a Betsabé»lo sitúa en la vida de David, después de la aventura amorosa con Betsabé y el asesinato de Urías. Al recordar aquel trasfondo, el poeta formula un principio teologal, que cualquier pecado es una ofensa a Dios, el autor de toda relación humana: "Contra ti, solo contra ti pequé». Al reconocer su crimen, David reconoció su culpa en su sentido comprensivo, cuando confesó: «he pecado contra el Señor» $(2 \mathrm{Sm} 12,13)$. En resumen, todo pecado se relaciona con el homicidio o con la reducción de la calidad de la vida, una ofensa contra la dignidad de la persona, tanto la de la víctima, como la del ofensor. La teología es conmovedora. Dado que el título se refiere al asesinato y adulterio, el poeta declara que una ofensa contra el prójimo equivale a una ofensa contra Dios, que todo pecado es, en un sentido radical, una privación de la vida, de la dignidad de la persona. Si se considera la demanda del salmo 50,18-20, el pecado actual consiste en una injusticia contra el prójimo.

Empezamos con la denuncia. La confesión de culpa en el salmo 51, el Miserere, es el acto seguido de la demanda del salmo anterior, el salmo 50. Los sacrificios que no agradan a Dios $(51,18-19$, «Los sacrificios no te satisfacen; si te ofreciera un holocausto, no lo querrías. Mi sacrificio es un espíritu quebrantado, un corazón quebrantado y humillado tú no lo desprecias» ${ }^{18}$, se denuncian en el salmo anterior (50, 16-20):

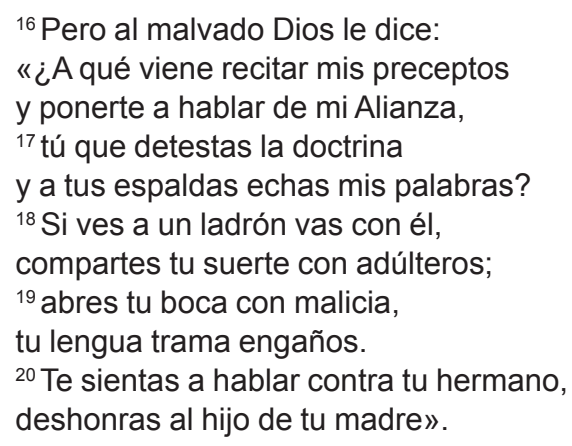

El profeta-salmista denuncia la incoherencia entre la teología sacerdotal y la vida práctica del presbítero, y el salmo 51 responde con una confesión de culpa

17. La conexión entre el salmo 51 y la persona de David se entiende por su confesión (v. 4), «Contra ti, solo contra ti pequé, cometí la maldad que aborreces», con la fórmula de la confesión de David en 2 Samuel (2 Sm 12, 13; cf. 2 Sm 11, 6-7; 12, 9). La expresión, «líbrame de la sangre [literal], oh Dios» (v. 16), implica el homicidio, que hace pensar en la ejecución de Urías; en el contexto del salmo significa la culpa.

18. Versión litúrgica. 
y la invocación a la misericordia ${ }^{19}$. El teólogo no es esclavo de las rúbricas. Sí, se había formado bien en el seminario; cumple con las rúbricas y los ritos prescritos; los conoce bien -el baño ritual (v. 4), el uso del hisopo (v. 9), los sacrificios (vv. 18.21)-, pero censura los ritos en cuanto no expresan una amistad vigente con Dios. El sacrificio apropiado es «un espíritu contrito, un corazón contrito y humillado» (v. 19). Con el espíritu nuevo y el trasplante del corazón (= la vida interior, con realce a la conciencia), nace el deseo de la vida evangélica (vv. 1417): «Devuélveme el gozo de tu salvación, afiánzame con espíritu generoso; enseñaré a los rebeldes tus caminos... aclamará mi lengua tu justicia». De la confesión del pecado y la misericordia de Dios nace el afán de anunciar la Buena Nueva y agradecer a Dios.

La teología del salmo nace del lenguaje y de las imágenes. La primera línea «Misericordia, Dios mío, por tu bondad [jésed] $»^{20}$ da el tono. El poeta no se justifica por sus méritos, por sus propias fuerzas a la penitencia; no convence a Dios con sus lágrimas o remordimiento por un pasado accidentado, sino acude sólo al jésed (fidelidad, traducido «bondad») de Dios y su «inmensa compasión» (hebreo, rajamîm, v. 3): «por tu inmensa compasión borra mi culpa»; así se abre a Dios y su jésed (= gracia, misericordia).

En una epíclesis, una invocación al Espíritu Santo ${ }^{21}$, el poeta pide a Dios la nueva existencia (v. 12): «Oh Dios, crea en mí un corazón puro, renuévame por dentro con espíritu firme». El verbo bara evoca el Génesis, cuando Dios llamó el mundo a la existencia con su palabra, y convirtió el caos en orden hermoso ( $G n$ $1,1)$. Isaías usa el verbo bara para señalar la transformación; lo que sale de su creación es algo nuevo y distinto (Is $65,17-18)^{22}$. Con el vocabulario de «crear» y «renovar», el poeta pide a Dios no una refacción, sino una nueva existencia, algo que no había antes. Y esta acción divina nace del jésed (= misericordia, bondad, fidelidad) del inicio del salmo: «Misericordia, Dios mío, por tu jésed» (v. 3).

En la creación, el espíritu divino aleteaba sobre el caos, mientras el mundo tomaba forma. En el salmo, un triple espíritu restaura al penitente: «Renueva en mi interior un espíritu firme, no retires de mi tu santo espíritu, afiánzame con espíritu generoso». El espíritu «firme» es raro; no se espera un calificativo

19. El salmo 51 tiene tres movimientos: la súplica para la purificación personal (vv. 3-11), la petición para la renovación personal y la celebración litúrgica válida (vv. 12-19) y, como consecuencia de la declaración de la restaurada ciudad santa y la liturgia válida (vv. 20-21).

20. Versión litúrgica.

21. El vocablo espíritu (hebreo, rûaj) se oye cuatro veces en el salmo (vv. 12-14.19). El recibir un espíritu nuevo, el respirar con el espíritu («aire») santo (cf. Gn 2, 7) y manifestar un espíritu generoso, requieren el sacrificio de «un espíritu quebrantado». Además, el «corazón puro» que favorece la nueva creación de Dios es el trasplante de «un corazón quebrantado y humillado» que el poeta ofrece a Dios (vv. 12.19). La acción divina, el «espíritu ('aire') santo» de Dios, salva al individuo y lo mantiene fiel (v. 13; cf. Is 63, 10-14).

22. «Pues he aquí que yo creo cielos nuevos y tierra nueva; antes habrá gozo y regocijo por siempre jamás por lo que voy a crear. Pues he aquí que yo voy a crear a Jerusalén 'Regocijo', y a su pueblo 'Alegría'»(cf. Is 41, 20; 45, 8.12). 
que connote la estabilidad y firmeza, aplicado al viento, al suspiro, al espíritu. «Firme» significa una constancia, una fuerza de voluntad para apartarse del pecado. El «santo» espíritu recuerda el suspiro de Dios, que es el aliento de vida desde la creación (cf. Gn 2, 7; 7, 22). Toda inhalación es prestada. Si Dios retiene su espíritu, la creatura deja de existir ${ }^{23}$. Con el tercer calificativo "generoso», el penitente no se conforma con un toque cosmético al diseño de Dios, sino pide una regeneración interior. Juntos, los tres vocablos describen la persona trasfigurada desde adentro, con determinación firme, alentada por el respiro de Dios, que se expresa en una vida generosa. Se vuelve una persona nueva, gracias a la misericordia (jésed) que se pide en el primer versículo.

La última súplica, que pide a Dios favorecer a Sión y reconstruir la ciudad (vv. 20-21), corresponde a la petición de que Dios cree un corazón nuevo y un espíritu nuevo. En la medida en que se vacía el individuo de su interés propio, se le llena del sentido común y se transforma su comunidad. En el grado en que la persona se deja renovar por la misericordia de Dios, la comunidad se edifica. En una ciudad restaurada, habitada por personas de corazón puro, se ofrecen los sacrificios correctos y una liturgia válida. La teología del salmo tiene resonancias con el corazón nuevo y el espíritu nuevo de Jeremías ${ }^{24}$ y Ezequiel (Ez $36,25-27)^{25}$ : «Los rociaré con agua pura y quedarán purificados; de todas sus impurezas y de todas sus basuras los purificaré. Y les daré un corazón nuevo, infundiré en ustedes un espíritu nuevo, quitaré de su carne el corazón de piedra y les daré un corazón de carne».

\section{PAstor AMABLE (Jn 10, 11-18): EL FACTOR DE LA DEBILIDAD}

El discurso del «Pastor Amable» llama la atención por aquello que calla o no dice; esperamos la reminiscencia de una escena pastoril -pastos verdes, aguas refrescantes, el camino correcto y el valle de sombras por donde el pastor conduce su rebaño-. Pero Jesús retrata al «Pastor Amable» con la frase, «yo doy mi vida por mis ovejas» (vv. 11.15.17), que introduce un viraje inesperado.

Desde el presupuesto vivencial, ¿no es normal que existen las ovejas para el bien del pastor? ¿Con qué fin sirve su oficio? Él cuida el rebaño, lo alimenta y abreva, lo conduce al redil al atardecer. El pastor busca la oveja extraviada,

23. El salmista escribe: «Les retiras tu soplo y expiran, y retornan a ser el polvo que son. Si envías tu aliento, son creados, y renuevas la faz de la tierra» (Sal 104, 29-30).

24. Jr 24, 7; 31, 33; 32, 39-40.

25. Algunos aspectos sugieren que el salmo 51 fue compuesto durante o después del destierro. Su lenguaje y teología recuerdan Jeremías, Ezequiel e Isaías 40-66. En el contexto del exilio, algunos puntos encuentran su sentido teológico, y la referencia a la restauración de los muros de la ciudad y la restitución de la liturgia del templo forman una conclusión apropiada. En todo caso, la idea de la restauración de la ciudad santa se transpone de un sentido literal hasta un sentido metafórico. 
adopta los corderos huérfanos y los cría con un frasco de leche, comparte con ellos el calor de la hoguera; él vigila que las ovejas no se descarríen ni se escapen y las cuida para taladrar la oreja -marcarlas como propiedad suya con un número- esquilarlas, matarlas y aprovechar de su lana y su carne. No tendría sentido tanto esfuerzo y cuidado si no recibiese un beneficio. Pero el evangelista tiñe la metáfora con otro colorante.

Contemplemos la escena en la estepa y el monte escarpado. Alzo la vista hacia el campo azul del cielo, enmarcado por los riscos y los taludes de la barranca. Ahí está el rebaño rebuscando los restos de comestible entre las rocas; oigo sus balidos babélicos. Ahí, en una repisa del precipicio, una oveja solitaria se adelantó para alcanzar la última brizna de hierba, y ahora ni avanza ni retrocede. Avanzar es desplomarse, herirse o matarse en las rocas abajo y no hay suficiente espacio para que dé la vuelta y marche atrás. Ahora aparece el pastor frenético, silbando, saltando y corriendo de aquí para allá para rescatar la oveja en peligro.

Si tuviéramos que asesorar la idoneidad de un candidato para el oficio de pastor, identificaríamos sus capacidades y aptitudes. ¿Posee el conocimiento adecuado de los animales? ¿Se adapta a la vida ruda? ¿Aguanta la vigilia nocturna? ¿Soporta largos periodos de soledad? ¿Puede atender a múltiples tareas a la vez? ¿Se mantiene la calma frente a los imprevistos?

En este test de aptitud todavía falta una cualidad para completar el perfil del «pastor Amable». ¿Se presta a dar su vida por sus ovejas? La aptitud del pastor incluye la pregunta, ¿es el candidato bastante débil para ser pastor? ¿Puede con el fracaso? ¿Su propia confusión y la duda de sí mismo lo hacen sensible a las necesidades y los miedos de las ovejas? ¿Alguna vez se le han agotado las esperanzas? ¿Alguna vez se extravió y pidió misericordia? En fin, ¿hasta qué grado se identifica el pastor con la oveja regular? ¿Ha conocido la misericordia en carne propia? Tal aptitud es necesaria porque la eficacia del «pastor amable» se mide por su deficiencia, dar su vida por sus ovejas.

La fragilidad y el sufrimiento son atributos esenciales de su perfil, que incluye la incapacidad, aun después del esfuerzo extremo, de lograr su meta. La fragilidad, más que militar en su contra, constituye parte esencial de su perfil de pastor.

Tales aparentes desventajas recuerdan la aprensión con que Moisés o Jeremías desempeñaban su vocación, o la sensación de indignidad de Isaías cuando Dios le llamó: «iAy de mí, que estoy perdido, pues soy un hombre de labios impuros» (Is 6, 5)! Saulo de Tarso se jactaba de su debilidad (2 Cor 11, 30): «Si hay que gloriarse, en mi flaqueza me gloriaré». Pablo escribe: «Y por eso, para que no me engría con la sublimidad de esas revelaciones, me fue dado un aguijón a mi carne, un ángel de Satanás que me abofetea para que no me engría. Por este motivo tres veces rogué al Señor que se alejase de mí. Pero él me dijo: 'Mi gracia te basta, que mi fuerza se realiza en la flaqueza'. Por tanto, con sumo 
gusto seguiré gloriándome sobre todo en mis flaquezas, para que habite en mí la fuerza de Cristo. Por eso me complazco en mis flaquezas, en las injurias, en las necesidades, en las persecuciones y las angustias sufridas por Cristo; pues, cuando soy débil, entonces es cuando soy fuerte» (2 Cor 12, 7-10).

El «Pastor Amable» conoce bien la flaqueza y el rechazo. Es sensible al cansancio y dolor, susceptible al desprecio. Él lloró por Jerusalén, expresó la tristeza frente a la muerte de un amigo, sufrió la falta de comprensión y la traición de sus amigos. El «Pastor Amable» fue débil y, como su Cuerpo que comparte en la Eucaristía, fue partido. Es su capacidad de sufrir, de ser partido y derramar su sangre, que lo cualifica como «Pastor Amable» quien da su vida por sus ovejas. En una palabra, es la misericordia.

Cuando Jesús despliega la imagen del «Pastor Amable» recalca una norma: «Conozco a mis ovejas y mis ovejas me conocen» $(10,14)$. ¿Quién entre las ovejas no tiene que esforzarse para enfrentar los retos con sensatez y honestidad, con la familia o la Iglesia, parroquianos o colegas? Pero es en aquellas situaciones donde nos acordamos que somos llamados a ser discípulos del «Pastor Amable», compartimos como él la condición humana y así logramos ser una fuerza redentora para las personas, que a nuestras tentaciones y desolaciones acompaña la gracia (= misericordia) de Dios que nos da una mayor sensibilidad. Como son tentadas las ovejas, como nosotros mismos sufrimos, así conoceremos al «Pastor Amable» quien primero nos conoció y respondemos al ser misericordiosos, porque conocemos en carne propia la misericordia.

La fragilidad nos identifica con el Pastor herido. La vida de la oveja no debe ser otra -sin la lucha, sin la duda de sí mismo, sin el sufrimiento y la conciencia de la propia incapacidad-. Es la experiencia de la fragilidad y limitación que nos identifica con el «Pastor Amable», quien nos guía por el valle tenebroso hacia las praderas verdes y los arroyos refrescantes. Hay un imperativo moral que nace de este argumento. Así como el «Pastor Amable» nos ama y nos da la vida, debemos hacer lo mismo el uno por el otro. Somos llamados a tolerarnos con suma paciencia las debilidades tanto físicas como morales ${ }^{26}$, perdonarnos mutuamente nuestras faltas, en una palabra, «ser misericordiosos como nuestro Padre es misericordioso» (Lc 6, 36).

La misericordia de Dios es mediada por la debilidad. El mandato del «Pastor Amable», que seamos misericordiosos como nuestro Padre es misericordioso, no se reduce a una norma general de la benevolencia. Este consejo define nuestra misión: Dios entró -por su debilidad- en nuestra naturaleza, y así llegó a ser el sacrificio eucarístico. En la debilidad nos identificamos con la compasión de Dios. Pablo escribió que, «en cuanto a mí, solo me gloriaré en mis flaquezas» (2 Cor 12, 5; cf. 13, 4-5.9). Es ridículo pensar que la caducidad define nuestra constitución temporal y luego despreciar a quienes son deficientes, tomar a

26. Benito de Nursia, Regla 72,5. 
mal a quienes son insensibles o torpes; permitir que nuestros desacuerdos se vuelvan hostilidades, o prolongar nuestros malentendidos y enojos. El hecho de pastorear no niega la verdad de que nosotros, antes de ser pastores, hemos nacido ovejas y de alguna forma seguimos siendo ovejas.

Contemplemos la figura del pastor desde la perspectiva de la oveja. Conoce bien los contratiempos; está consciente de los extravíos, de los callejones sin salida. La oveja una que otra vez se ha encontrado en valles oscuros y peligrosos. Se ilusiona con una vida más sana, una caminata más segura, pero no siempre la lleva a cabo; quiere convertirse, caminar recto, pero siente que ya se haya desviado o que le impida el «aguijón en su carne» (cf. 2 Cor 12, 7), piensa que su crecimiento o aprendizaje vayan demasiado lento y que haya demasiado en su contra. La oveja siente la propia incapacidad de responder a lo que se le pide; no se salva a sí misma. Pero la Buena Nueva es que nuestro «Pastor Amable» es también Cordero - «Cordero de Dios que quita el pecado del mundo»-. El «Pastor Amable», por ser Cordero, mira a las ovejas y conoce bien nuestras debilidades y temores, cuán fácil es desanimarnos y descarriarnos $\mathrm{y}$, como Cordero, entregó su vida para que todo el rebaño tenga vida. En este doble intercambio maravilloso - del cordero que se hace Pastor y luego se vuelve el Cordero sacrificado- aprendemos algo: ahora nos toca ofrecernos para que la hermana o el hermano tengan vida abundante. Nos toca replicar el ejemplo del Pastor Misericordioso que se sacrificó para la vida del rebaño. ¿No llamamos a esta virtud, en términos bíblicos, jésed-fidelidad, que se vive en términos de misericordia y compasión?

\section{MAGDA: ¿QUIÉNES SE SALVAN?}

Un día, María Magdalena, frente al Crucifijo en su gruta cerca de Aix en Provence, contemplaba el misterio de la salvación y el dicho de Jesús: "No necesitan médico los que están fuertes, sino los que están mal» (Mc 2, 17; cf. Lc 5, 31); y también: «Los publicanos y las prostitutas llegan antes que ustedes al Reino de Dios» (Mt 21, 31). Ella preguntó al Crucificado, que extendía sus brazos abiertos: "Los israelitas antes de Cristo, que se dieron a la idolatría, ¿son ellos salvados?». Le contestó el Crucificado: «Mi pueblo elegido tiene un campo amplio en mi corazón, puesto que son el conducto de la misericordia hacia todas las naciones del mundo».

Magdalena reflexionó un poco y le preguntó: «¿Qué hay de los idólatras, pueblos vecinos de Israel, los que no creían en Dios y fabricaban sus propios dioses? ¿Son salvados?».

«Los idólatras que se dedicaron a practicar la justicia y la misericordia, sí se salvan por sus obras», respondió Cristo, «solo que en el cielo Dios se esconde un poco, para que los idólatras no sientan vergüenza de su error».

Magda preguntó: "Y los babilonios, egipcios y asirios, que tanto daño hicieron a tu pueblo Israel, ¿son salvados aquellos?».

Cristo respondió: «Aquellos pueblos infames, prepotentes, imperialistas, además del mal que hacian, eran instrumentos en manos de mi Padre para castigar e instruir a Israel. 
La verdad, había muchas personas sencillas entre ellos, junto con los animales, que 'ni sabían distinguir entre su mano derecha y su mano izquierda' (Jn 4, 11). Sí, Dios es misericordioso para aquellas naciones opresoras».

Magda insistió: "Y Moisés, un asesino; y David, asesino y adúltero; o Judas, el traidor, o bien Saulo de Tarso, que persiguió a los creyentes, ¿aquellos son salvados?».

Respondió el colgado de la Cruz: «Por esto estoy aquí, para que también los asesinos, los adúlteros y los que me persiguen se salven».

«Entonces, Señor», prosiguió Magda, desconcertada: «¿No es necesario creer en ti para salvarse?».

Le sonrió el Crucificado, sus brazos abiertos: «Todos los que sientan compasión y practican la misericordia creen en mí, aunque no crean. Yo encarno la misericordia; quien tiene misericordia confiesa mi religión, aunque no me conozca. Lo que salva al ser humano es la misericordia. Si la persona que la practica no cree en mí, eso no importa: yo creeré en ella. De todas las religiones se puede dudar, pero nadie puede dudar de la misericordia, que es la salvación».

Magda: "Ya voy a acabar con mis impertinencias. Pero me pregunto sobre la salvación de los sacerdotes violadores y los obispos que los encubren».

El Crucificado: «Pusiste el dedo en la llaga. Aquellos sacerdotes y las personas del alto rango y de la plebe que los encubren, dañan a toda la sociedad y solapan crímenes indecibles. Hay que poner alto a todo crimen y tratar al criminal. Sin embargo, como Dios es capaz de sacar bien del mal, en la actualidad, con esta crisis en la sociedad, Dios ofrece una oportunidad de sanar a la misma sociedad. Es bien sabido que el exceso de poder, la violación de la dignidad y los derechos, el abuso de los niños y los desprotegidos, no está limitado a los ministros de la Iglesia. La misma sociedad sufre de esta plaga. Pero la sociedad a veces no se siente con las herramientas en las manos para evitar la violación de la dignidad, tratar la herida, denunciar la injusticia y sanar las víctimas. Entonces, la sociedad, al señalar a la Iglesia con el dedo, exige que, en este ámbito, se arreste el crimen, se limpie la casa, para dar pauta a la misma sociedad para seguir el ejemplo».

«Una pregunta más: ¿Y qué hay de los pastores promedio, los presbíteros ordinarios, ¿ellos se salvan?».

«El presbítero, por el hecho de ser presbítero, no se salva. El presbítero, por servir a Dios con sincero corazón, por imitar a Cristo, por recibir la misericordia divina y por practicarla, por el bien que obra y el mal que evita, encuentra un campo muy amplio en mi corazón. Pero el presbítero de corazón duro, que se pastorea a sí mismo antes que a su pueblo, que juzga a su prójimo, que le cierra la puerta a la misericordia a los necesitados, no encuentra la felicidad que desea. A fin de cuentas, la pregunta clave no es si fulano o zutano de tal se salvarán. Es más bien, si quieren ser salvados».

Con esta conversación Magda tenía una noción clara sobre la salvación, y se propuso practicar la verdadera religión católica: la de la misericordia. 